\title{
Improvements in the Root Morphology, Physiology, and Anatomy of Platycladus orientalis Seedlings from Air-root Pruning
}

\author{
Zhipei Feng and Xitian Yang ${ }^{1}$ \\ College of Forestry, Henan Agricultural University, Zhengzhou 450002, \\ Henan, China
}

\section{Hongyan Liang}

College of Forestry, Henan Agricultural University, Zhengzhou 450002, Henan, China, and Sanmenxia Polytechnic, Sanmenxia 472000, Henan, China

\author{
Yuhua Kong \\ College of Forestry, Henan Agricultural University, Zhengzhou 450002, \\ Henan, China
}

\section{Dafeng Hui}

Department of Biological Sciences, Tennessee State University, Nashville, TN 37209

Jiabao Zhao, Erhui Guo, and Beibei Fan

College of Forestry, Henan Agricultural University, Zhengzhou 450002, Henan, China

Additional index words. air-root pruning, root growth, chinese cypress

\begin{abstract}
Air-root pruning (AP) has been identified as an effective technique for enhancing root growth and development. However, little information is available regarding the temporal changes in the root system of Platycladus orientalis (L.) Franco under AP. We performed integrated morphological, physiological, and anatomical analyses of the roots in $P$. orientalis seedlings that had been air-root pruned for 120 , 150, and 190 days. Our results found that the whole root length, number of root tips, and root surface area of AP seedlings at 120, 150, and 190 days were higher than those of the non-root-pruned (NP) seedlings $(P<0.05)$, but the average root diameter did not differ significantly between the treatments. Compared with NP treatment, AP increased the root length, surface area, number of tips, and specific root length of the $\leq 0.5 \mathrm{~mm}$ diameter roots in $P$. orientalis during the experimental periods $(P<0.05)$, but those of 0.5 - to 1 -mm-diameter roots were only increased on day $190(P<0.05)$. The AP plants also exhibited higher root vitality and proportion of live fine roots than the NP plants $(P<0.05)$. Our anatomical evaluation of the $\leq 0.5 \mathrm{~mm}$ roots and taproots revealed features that could account for the morphological differences found between the AP and NP plants. In conclusion, our results indicate that air-root pruning induced changes in the roots that promote the root system development in $P$. orientalis compared with the NP treatment during the experimental period. These results thus provide experimental evidence to support the use of AP in $P$. orientalis seedlings.
\end{abstract}

Received for publication 11 July 2018. Accepted for publication 14 Oct. 2018.

We thank members of team 129 for assistance in the field and laboratory.

The funding for this research was provided by National Natural Science Foundation of China (31570613, 41501331) and Plan for Scientific Innovation Talent of Henan Province (154200510019).

X.Y. and Z.F. conceived and designed the experiments. Z.F., H.L., J.Z., E.G., and B.F. performed the experiments. Z.F. and Y.K. analyzed the experimental data. Z.F. wrote the manuscript. X.Y. and D.H. edited and proofread the manuscript. All authors read and approved the manuscript.

${ }^{1}$ Corresponding author. E-mail: xitianyang@henau. edu.cn.
Root structure is crucial for plant adaptation to changing environments and plays a pivotal role in determining root functionality (Dara et al., 2015; Seago and Fernando, 2013; Sun et al., 2008). A well-developed and well-structured root system, consisting of a balanced combination of fine and coarse roots, is optimum for rapid growth and successful establishment after transplantation (Davis and Jacobs, 2005; Dey et al., 2010; Dumroese et al., 2013; Perrig et al., 2007). Restoration using container seedlings instead of bare-root seedlings has become increasingly common owing to its multiple advantages with respect to increased survival and growth benefits
(Dumroese et al., 2013; Liu et al., 2016; Tsakaldimi et al., 2005; Villar-Salvador et al., 2012; Watson and Tombleson, 2002). For an individual plant grown in a container, however, root malformation (i.e., root spiraling, cycling, and matting) is a major limiting factor because it could result in partial or complete root death (Dumroese et al., 2013; Lindström and Rune, 1999; Liu et al., 2016; Ortega et al., 2006; Takoutsing et al., 2014), directly impeding a series of physiological processes (Dumroese et al., 2013). Eliminating root malformation in container seedlings is thus necessary for meeting the increased demands for vegetation restoration.

Over the past decade, AP has evolved into a particularly effective means of mitigating root malformation and regulating root growth in container-seedling production and functions by stopping root extension by exposing the roots to relatively dry air (Amoroso et al., 2010; Campbell et al., 2006; Mariotti et al., 2015; Marler and Musser, 2016; Rune, 2003; Ortega et al., 2006; Van Sambeek et al., 2016). Related experiments with Pinus contorta Dougl. var. latifolia Engelm. and Pinus radiata D. Don seedlings have discovered that AP can modify root system architecture and ultimately enhance seedlings growth and survival in the field (Campbell et al., 2006; Ortega et al., 2006). Consistent with these results, Rune (2003) and Van Sambeek et al. (2016) found that AP seedlings exhibited improved lateral root growth and presented a greater root mass relative to the NP seedlings, which might confer a survival advantage after transplantation (Marler and Musser, 2016). Contrary to the positive reports of AP, Amoroso et al., (2010) documented that root biomass declined following AP due to root loss and reduced root regeneration. The observed differences between these results may be due to differences in the planting sites (Campbell et al., 2006) or the dimensions of the AP containers (Mariotti et al., 2015). The preceding studies have primarily focused on the root architecture and survival rate associated with AP. To date, little information is available on the temporal changes in root morphology, physiology, and anatomy of seedlings in response to AP.

Platycladus orientalis (L.). Franco, a native Chinese Cupressaceae plant, is among the most intensively used cypress species for vegetation restoration projects in northern China (Jiang et al., 2014; Li et al., 2016). This indigenous species is a perennial evergreen coniferous tree with remarkable longevity that exhibits high tolerance to a diversity of adverse environmental conditions, including drought, freezing temperatures, hot weather, and nutrient imbalances (enrichment and depletion) (Jiang et al., 2014; Li et al., 2016; Wu et al., 2017; Zhang et al., 2017). Other studies have demonstrated that $P$. orientalis provided considerable ecological benefits for vegetation restoration, especially in fragile ecosystems such as arid and semiarid regions (Yu et al., 2015; Zhang et al., 2017). However, its survival rate is low due to the poorly developed root systems of container seedlings (Yang et al., 2010; 2011) coupled with the extreme environments in which they are transplanted (Cui et al., 2017). We previously found that AP could be used to develop a relatively well-grown root system that increases survival of $P$. orientalis seedlings 
compared with NP seedlings (Yang et al., 2010; 2011). Although we have also reported on considerably different biomass allocation patterns of AP and NP P. orientalis seedlings, the way in which the roots respond to AP has not yet been documented.

The main objectives of the present study were to 1) assess how the AP treatment influences changes in the morphology of whole root and fine roots, 2) evaluate the differences in the anatomical response of the taproots and fine roots to $\mathrm{AP}$ at 120,150 , and $190 \mathrm{~d}$, and 3) evaluate the efficacy of AP in P. orientalis.

\section{Materials and Methods}

\section{Experimental facility}

This research was conducted in a greenhouse at the forestry ecological experimental station of Henan Agricultural University (lat. $34^{\circ} 43^{\prime} \mathrm{N}$, long. $113^{\circ} 42^{\prime} \mathrm{E}$ ), Henan Province, China. The study site conditions during the entire growth period were as follows: air temperatures ranged from 22 to $33{ }^{\circ} \mathrm{C}$, the relative humidity was between $50 \%$ and $65 \%$, and there was $\approx 12$ to $14 \mathrm{~h}$ of daylight.

\section{Experimental design and plant material}

The $P$. orientalis seeds for this research were collected by the Jiyuan City Forestry Administration of Henan Province in China from Oct. to Nov. 2015. The seeds were transported to the laboratory and refrigerated in transparent plastic bags. At the beginning of the experiment, the $P$. orientalis seeds were surface disinfected with $3 \%$ $\mathrm{H}_{2} \mathrm{O}_{2}$ for $30 \mathrm{~min}$, rinsed several times in sterile water, and soaked in distilled water for $48 \mathrm{~h}$. Then, the sterilized seeds were germinated in a plastic pot over a period 15 to $20 \mathrm{~d}$ at room temperature ( $18 / 24{ }^{\circ} \mathrm{C}$, night/day). The germination rate was $\approx 94 \%$. After germination, the $P$. orientalis seeds were sown into soil blocks of 10 $\mathrm{cm} \times 10 \mathrm{~cm} \times 10 \mathrm{~cm}$ (length $\times$ width $\times$ height) and ordinary plastic containers of the same dimensions. Each treatment had 180 seedlings. The soil blocks were specially designed for use in an AP system (Yang et al., 2010). The seedlings grown in the soil blocks were thus considered as the AP-treated plants, while those growing in ordinary plastic containers were the NP plants (Fig. 1). The growth medium for both treatments contained a 2:1:1:1 (by volume) mixture of organic soil, sand, loam, and vermiculite with $5 \mathrm{~g} \cdot \mathrm{L}^{-1}$ of a slow-release $6: 18: 14(\mathrm{~N}-\mathrm{P}-\mathrm{K})$ watersoluble fertilizer and $1 \mathrm{~g} \cdot \mathrm{L}^{-1}$ of a binding agent (Yang et al., 2010; Yang et al., 2011). All seedlings were evenly arranged on wire mesh (pore size $2 \mathrm{~mm} \times 2 \mathrm{~mm}$ ) placed $20 \mathrm{~cm}$ above the ground (Fig. 1), following a randomized complete block design. The planting space was $5 \mathrm{~cm}$ $\times 5 \mathrm{~cm}$ on the screen (Fig. 1). To ensure the same water availability, the growth medium water content was measured daily with a Theta Probe soil moisture sensor ML2x (Delta-T Devices, Cambridge, UK), and each treatment was watered to a certain weight every $2 \mathrm{~d}$. Pest management and weed control were practiced during the growth period of $P$. orientalis. It took $30 \mathrm{~d}$ for the roots of seedlings in the soil blocks to grow beyond the growing medium and show AP effects (Feng et al., 2017). Healthy seedlings with an approximately uniform height were selected as the testing samples on the 120th, 150th, and 190th days during the AP period.

\section{Root sampling and measurements}

Root sampling and measurements of root morphology. Nine $P$. orientalis seedlings in each treatment were harvested, numbered, and wrapped in sealable plastic bags to prevent water loss from 09:00 AM to 11:00 AM on the 120 th, 150th, and 190th days of AP. The samples were promptly taken to the laboratory for measurements of morphological characteristics. Each plant was separated into shoots and roots at the root collar using a sharp razor blade. The roots were immersed in deionized water to remove soil particles and then washed with tap water to remove all the remaining soil. The roots were then carefully divided into the following three root diameter classes: $\leq 0.5 \mathrm{~mm}, 0.5-1 \mathrm{~mm}$, and $1-2 \mathrm{~mm}$. All sampled roots were scanned using a scanner (EPSON PERFECTION V700 Photo, Japan) with a transparency adapter at $300 \mathrm{dpi}$. The total root length (RL, cm), root surface area $\left(\mathrm{RSA}, \mathrm{cm}^{2}\right.$ ), average root diameter (ARD, $\mathrm{mm}$ ), and number of root tips (RT) of each sample were directly analyzed using specific computer image analysis software (WinRhizo Pro 2007d, Regent Instruments, Canada). After root scanning, all root samples were oven-dried at $75{ }^{\circ} \mathrm{C}$ for $48 \mathrm{~h}$ and carefully weighed to the nearest $0.1 \mathrm{mg}$. Specific root length (SRL, $\mathrm{m} \cdot \mathrm{g}^{-1}$ ) was calculated as the ratio of root length and root dry weight of the corresponding root system.

Root vitality measurement using the triphenyltetrazolium chloride method. Nine fresh fine root (diameter $\leq 2 \mathrm{~mm}$ ) samples were used for separating live roots from dead roots and nine fresh fine roots were used for root vitality analysis for each treatment at each sampling day. The live fine roots were separated from dead roots based on color and tensile strength (McClaugherty et al., 1982; Reinmann and Templer, 2015). Root vitality analysis was used the 2,3,5-triphenyltetrazolium chloride (TTC) method according to the standard procedures of Ruf and Brunner (2003) with some modifications. This vitality assay is based on the reduction of TTC to water-insoluble reddish triphenylformazan (TF) by mitochondrial dehydrogenase activity, which is regarded as an index of root tissue vitality (Comas et al., 2000). Nine roots were sampled ( $\approx 500 \mathrm{mg}$ fresh weight) from each treatment at each sampling day, including three independent replications with three individuals in each replication. The fresh root samples were overdried at $60{ }^{\circ} \mathrm{C}$ for $48 \mathrm{~h}$ and carefully weighed to the nearest $0.1 \mathrm{mg}$. Root

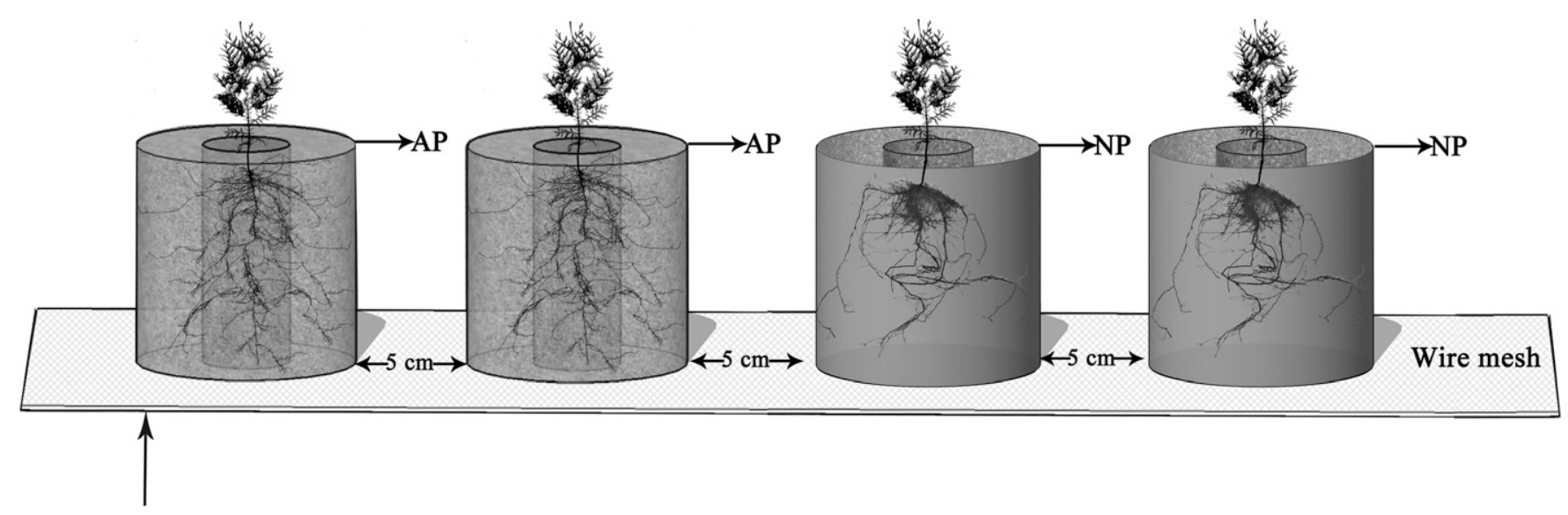

$20 \mathrm{~cm}$

\section{Ground}

Fig. 1. P. orientalis seedlings between the air-root-pruning (AP) and non-root-pruning (NP) treatments. 
vitality was expressed as absorption of TF per gram dry mass at $520 \mathrm{~nm}$.

\section{Assessments of root anatomy}

On each sampling day, nine taproots were carefully harvested per treatment, as close as possible to $10 \mathrm{~cm}$ from stem-root connection, as well as the first-order roots in the proximity of the root tips at room temperature to calculate the anatomical parameters of the root system. Each root sample was carefully dissected using forceps according to the branch order, following the approach described in Pregitzer et al. (2002) and Wang et al. (2006), regarding the distal nonwoody roots as first-order roots. Subsequently, a 5mm-long segment of each root sample was immediately fixed for $72 \mathrm{~h}$ in FAA $(5 \mathrm{~mL}$ of $37 \%$ formalin, $5 \mathrm{~mL}$ of $100 \%$ glacial acetic acid, $90 \mathrm{~mL}$ of $70 \%$ ethanol). Samples were then rinsed successively in gradient ethanol $(70 \%, 50 \%$, and $30 \%, \mathrm{v} / \mathrm{v})$ and distilled water (30 min in each), stained with $1 \%$ safranin $\mathrm{O}$ for $48 \mathrm{~h}$, dehydrated in a graded alcohol series $(70 \%, 85 \%, 95 \%, 100 \%$, v/v; $30 \mathrm{~min}$ each), and then embedded in ceresin wax. Ten-micrometer-thick transverse sections were sliced off from each root sample by a Leica SM 2400 microtome fitted with a dry glass knife. All the sections were dewaxed twice with dimethylbenzene for $15 \mathrm{~min}$ and $25 \mathrm{~min}$, dehydrated with an equivalent volume mixture of ethanol and dimethylbenzene, ethanol $(100 \%, v / v)$, and then ethanol $(95 \%, \mathrm{v} / \mathrm{v})$, and dyed with $0.5 \%$ fast green for $20 \mathrm{~s}$. The images of slides were observed with a light microscope (BX43, Olympus, Japan) under transmitted light and were photographed using a digital camera (Camedia C4040, Olympus, Germany). All digitized photographs were observed at $\times 20$ objective magnification. The CellSens Standard software (Olympus) was used to measure the root cross section, cortical thickness, and stele diameter. The ratio of the stele to root diameter was estimated as the stele diameter of root samples divided by the corresponding diameter.

\section{Statistical analysis}

All statistical analyses were performed using IBM SPSS Statistics for Windows, Version 21.0 (IBM Crop., Armonk, NY). A single multivariate analysis was used to assess significant differences among the treatments at the three sampling points in terms of root morphology (RL, RSA, ARD, RT, and SRL), root vitality and anatomy (root cross section, cortical thickness, stele diameter) characteristics. Means were compared for significance using the least significance difference test at a 5\% significant level. All data and graphs were postprocessed in Excel 2010 and Origin (Version 8.5, OriginLab Software Corp., Northampton, MA), respectively.

\section{Results}

Root morphological characteristics of $P$. orientalis under $A P$. The RL, RT, and RSA of the plants subjected to AP for 120,150, and
$190 \mathrm{~d}$ were higher than those of the NP plants $(P<0.05)$. The RL of AP was $\approx 0.57,0.37$, and 0.21 times longer than that of the NP treatment on the corresponding sampling days $(P<0.05$; Fig. 2A). Similarly, RT followed the same pattern, increasing from 180 to 578 , and was higher in AP than in the NP treatment $(P<0.05$; Fig. 2C). After 120, 150, and $190 \mathrm{~d}$ of the AP treatment, RSA was higher (i.e., 17.86, 38.49, and $\left.57.20 \mathrm{~cm}^{2}\right)$ than the NP treatment $(10.07$, 22.06 , and $\left.37.13 \mathrm{~cm}^{2}\right)(P<0.05$; Fig. $2 \mathrm{D})$. However, ARD was marginally lower in the AP treatment, but this difference was not statistically significant (Fig. 2B).

Effects of $A P$ on fine root system morphology of $P$. orientalis. The AP treatment significantly stimulated the growth of the smallest fine roots ( $\leq 0.5 \mathrm{~mm}$ diameter $)$ in terms of several root morphological characteristics (RAL, RT, RSA, and RSL) ( $P<$ $0.05)$, but this was more pronounced in the 0.5 - to $1-\mathrm{mm}$ roots (only at $190 \mathrm{~d}$ ). The average RL values of the $\leq 0.5 \mathrm{~mm}$ roots ranged from 78 to $149.9 \mathrm{~cm}$; RT ranged from 170 to 537; RSA ranged from 6.3 to $12 \mathrm{~cm}^{2}$; and SRL ranged from 7.3 to $9.4 \mathrm{~m} \cdot \mathrm{g}^{-1}$ in the AP treatment from 120 to $190 \mathrm{~d}$. Compared with the NP seedlings, those treated with AP had an enhanced RL for the $\leq 0.5 \mathrm{~mm}$ roots at 120, 150, and $190 \mathrm{~d}(P<0.05$; Fig. 3A).
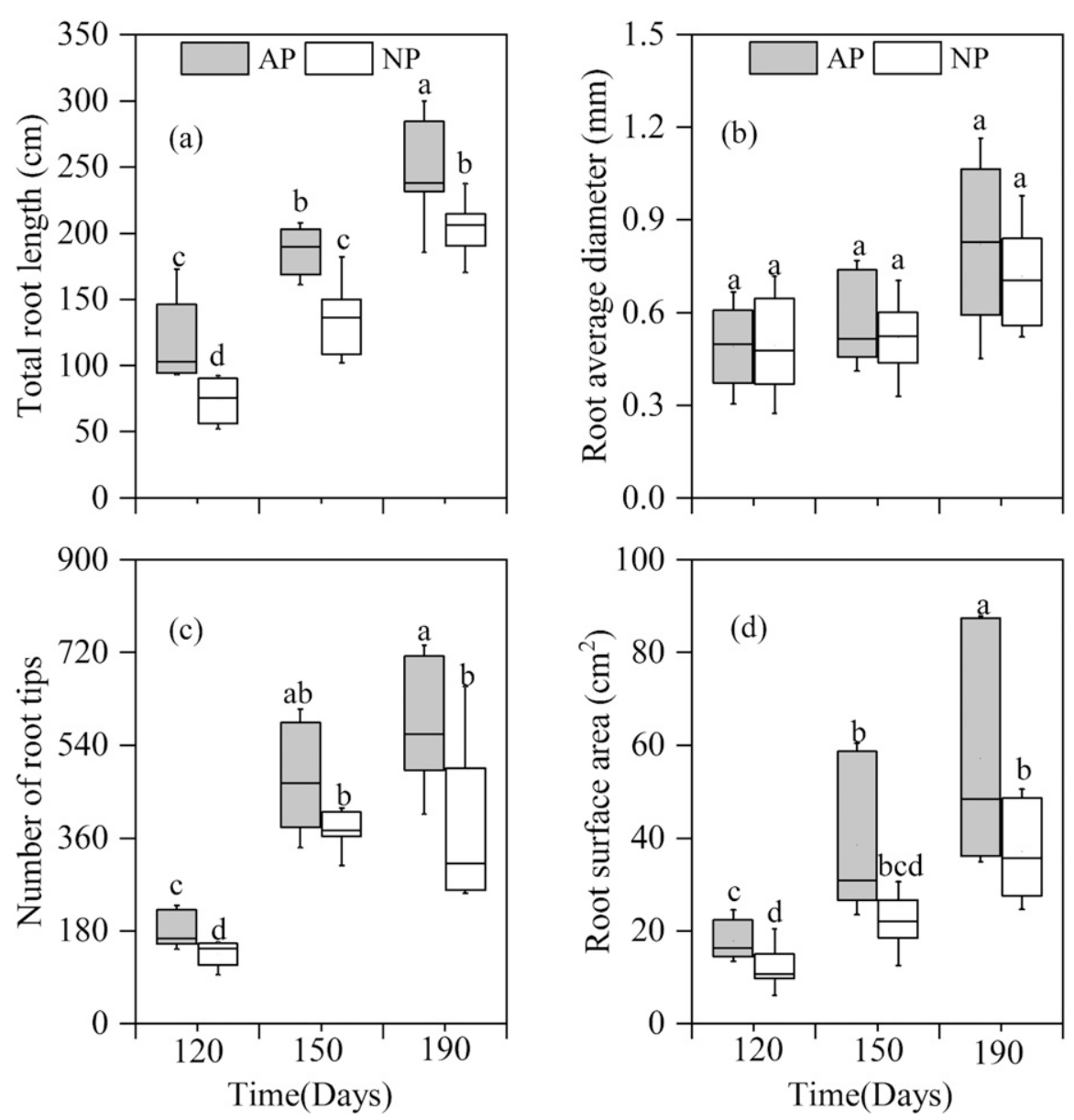

Fig. 2. Total root length, root average diameter, root tips, and root surface area between the air-rootpruning (AP) and non-root-pruning (NP) seedlings at 120, 150, and $190 \mathrm{~d}$. Different lowercase letters represent significant differences $(P<0.05)$ in root traits among different treatments according to Fisher's least significant difference test.

Similarly, the RT of the $\leq 0.5 \mathrm{~mm}$ roots was higher at 120,150 , and $190 \mathrm{~d}$ of the AP treatment when compared with the NP treatment $(P<0.05$; Fig. 3D). The RSA of the $\leq 0.5 \mathrm{~mm}$ roots was $62 \%, 32 \%$, and $14 \%$ higher in the AP treatment at 120,150 , and 190 d relative to the NP treatment $(P<0.05$; Fig. $3 \mathrm{G})$. The SRL of the $\leq 0.5 \mathrm{~mm}$ roots tended to be longer in the AP seedlings compared with the corresponding roots in the NP treatment, with differences observed only at 150 and $190 \mathrm{~d}(P<0.05$; Fig. 3J). Indeed, all of the investigated morphological parameters for 0.5 - to $1-\mathrm{mm}$ roots under AP had higher values than those under NP at the end of the experiment (190 d) $(P<0.05)$, but no such significant differences were detected on days 120 and 150 (Fig. 3B, E, H, and K). No significant changes were observed for 1to 2-mm roots (Fig. 3C, F, I, and L).

Differences in the proportion of fine roots and root vitality between the AP and NP treatments. The proportion of live fine roots ( $\leq 2 \mathrm{~mm}$ ) increased to $77 \%, 84 \%$, and $87 \%$ in the AP treatment at 120,150, and $190 \mathrm{~d}(P<$ 0.05 ; Fig. $4 \mathrm{~A})$. The $P$. orientalis seedlings showed higher root vitality in the $\leq 2 \mathrm{~mm}$ roots at 120,150 , and $190 \mathrm{~d}$ after $\mathrm{AP}$ compared with those of NP $(P<0.05$; Fig. 4B). 

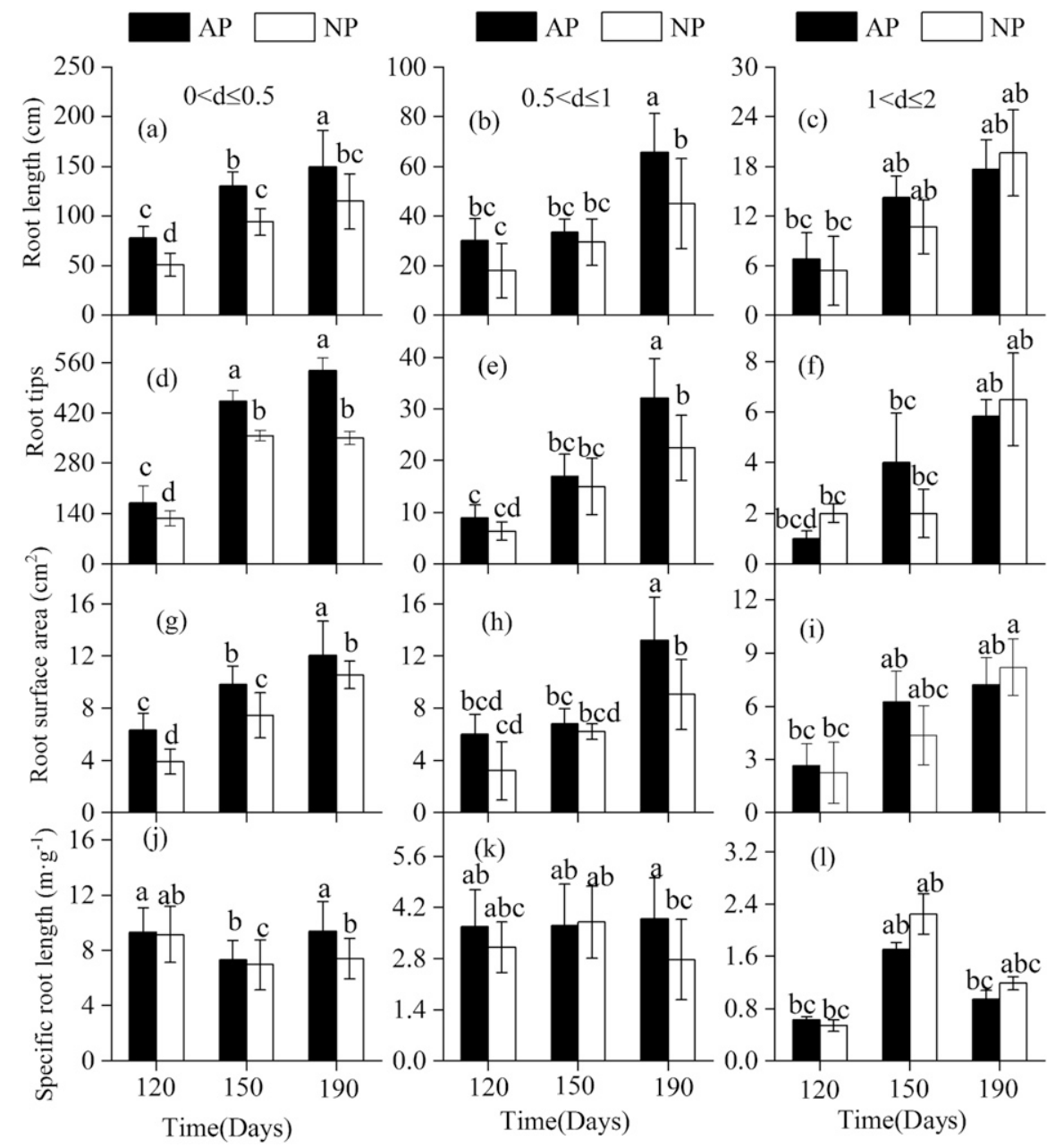

Fig. 3. Total root length $(\mathbf{A}-\mathbf{C})$, number of root tips $(\mathbf{D}-\mathbf{F})$, root surface area $(\mathbf{G}-\mathbf{I})$, specific root length $(\mathbf{J}-\mathbf{L})$ of $P$. orientalis roots of diameter $\leq 0.5,0.5-1$, and $1-2 \mathrm{~mm}$ between the air-rootpruning (AP) (left panel) and non-root-pruning (NP) (right panel) treatments at 120,150, and 190 d. The bars indicate the standard error $(n=9)$. Different lowercase letters represent significant differences $(P<0.05)$ in root traits among treatments according to Fisher's least significant difference test.
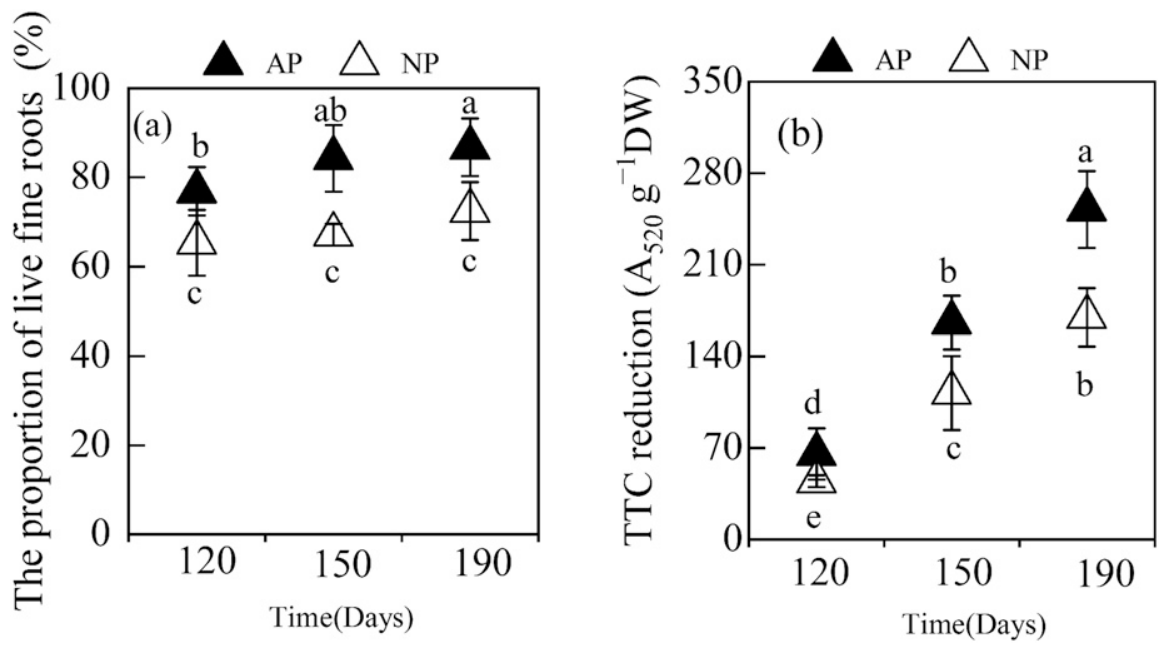

Fig. 4. The proportion of live fine roots and root activity under the air-root pruning (AP) and nonroot-pruning (NP) treatments at 120,150 , and $190 \mathrm{~d}$. The bars indicate the standard error $(n=9$ in left zones; $n=3$ in right zones). Different lowercase letters represent significant differences $(P<0.05)$ in root traits among different treatments according to Fisher's least significant difference test.

$P$. orientalis root responses to $A P$ at the anatomical level. On the basis of the mean value across the three sampling times, differences were observed for root cross section, cortical thickness, and stele diameter $(P<$ 0.05 ; Fig. $5 \mathrm{~A}-\mathrm{C}$ ), while no differences were found in the stele to root diameter ratio among the different treatments (Fig. 5D). Root cross section, cortical thickness, and stele diameter (apart from $120 \mathrm{~d}$ ) of the $\leq 0.5 \mathrm{~mm}$ roots were lower at each sampling time in the AP than in the NP treatment $(P<$ $0.05)$. Root cross section in the AP treatment was smaller than the NP seedlings at 120 , 150 , and $190 \mathrm{~d}(P<0.05$; Fig. 5A). The cortical thickness of the $\leq 0.5 \mathrm{~mm}$ roots in the AP treatment on day 120,150 , and 190 was $58.52,78.69$, and $88.3 \mu \mathrm{m}$ lower than the corresponding values $(76.96,89.56$, and $126.5 \mu \mathrm{m})$ found for the NP seedlings $(P<$ 0.05 ; Fig. 5B). In addition, the stele diameter values of the $\leq 0.5 \mathrm{~mm}$ roots under AP were $7.71,12.38$, and $26.98 \mu \mathrm{m}$ lower than those calculated for the corresponding root class of the NP treatment on day 120,150 , and 190 (Fig. 5C).

The AP seedlings had lower taproot lengths compared with the NP treatment at all sampling times $(P<0.05$; Table 1$)$. Taproot cross sections of the AP seedlings at 150 and $190 \mathrm{~d}$ were, respectively, $15.69 \%$ and $23.88 \%$ larger than those of the NP plants $(P<0.05$; Table 1$)$. Although the cortical thickness of the taproot was similar between the AP and NP treatments during the first 120 $\mathrm{d}$, it increased in AP at 150 and $190 \mathrm{~d}(P<$ 0.05; Table 1). However, for all 3 sampling days, the stele diameter of taproots did not differ significantly between the AP and NP treatments (Table 1).

\section{Discussion}

Root morphological characteristics are associated with root function (Alameda and Villar, 2012; Perrig et al., 2007; Rao et al., 2016; Tian et al., 2014). Well-developed and well-structured root systems are associated with increases in water and nutrient absorption and the photosynthetic rate (Alameda and Villar, 2012; Davis and Jacobs, 2005; Dey et al., 2010; Perrig et al., 2007), thereby positively influencing plant adaptation and field performance after transplantation (Davis and Jacobs, 2005; Dumroese et al., 2013; Marler and Musser, 2016; Rao et al., 2016). In our study, the root morphological characteristics (i.e., RL, RT, and RSA) of $P$. orientalis were significantly higher in the AP-treated seedlings than the NP seedlings during the experimental periods (Fig. 2), suggesting that root growth was improved under AP. Our findings were similar to those in Serianthes nelsonii Merr. (Marler and Musser, 2016) and Quercus bicolor Willd. (Van Sambeek et al., 2016) seedlings. Both Yang et al. (2011) and Feng et al. (2017) reported that AP had no effect on the root-toshoot ratio of $P$. orientalis compared with the NP treatment but did increase the aboveground and total biomass (Feng et al., 2017). 
Therefore, the improved root system $P$. orientalis after AP might contribute to the higher total biomass (Close et al., 2010; Feng et al., 2017). Higher total biomass is linked to larger carbohydrate stores available (Close et al., 2010), thus suggesting the growth of seedlings (Tsakaldimi et al., 2013; Yang et al., 2011). terms of water and nutrient uptake (McCormack et al., 2015; Perrig et al., 2007). Some investigators have also found that fine roots are involved in the synthesis of certain growth hormones and associated with root adaptations for survival in changing environments (Di Iorio et al., 2016; Makita et al., 2016; Mosca et al., 2017). We found that the fine roots $(\leq 0.5 \mathrm{~mm})$ of $P$. orientalis seedlings under AP had significantly higher RL, RT, RSA, and SRL (except for $120 \mathrm{~d}$ ) compared with NP at 120, 150, and $190 \mathrm{~d}$ (Fig. 3), with the AP seedlings would be higher than NP

Fine roots, especially $\leq 0.5-\mathrm{mm}$ roots, perform important physiological functions in

all responses being driven mainly by the enhanced formation of $\leq 0.5 \mathrm{~mm}$ roots. These results suggest that AP-treated seedlings of $P$. orientalis might possess a greater ability to adapt to increased competition and exploit belowground resources (Di Iorio et al., 2016; Perrig et al., 2007). In parallel, we only observed a significant increase in RL, RT, RSA, and SRL of 0.5- to 1-mm roots after AP on the 190th day, thus associating it to the long-term effect of AP. Taken together, these results suggest that $P$. orientalis can optimize its root morphology and structure via the differential alteration of fine roots under AP. This type of strategy is consistent with the findings of several published reports (Dong et al., 2016; Sudmeyer et al., 2004).

In addition to the modified root morphology, we further found that the proportion of all live fine roots $(\leq 2 \mathrm{~mm})$ in $P$. orientalis was slightly stimulated by AP (Fig. 4A). This result may be interpreted as a thigmomorpho-
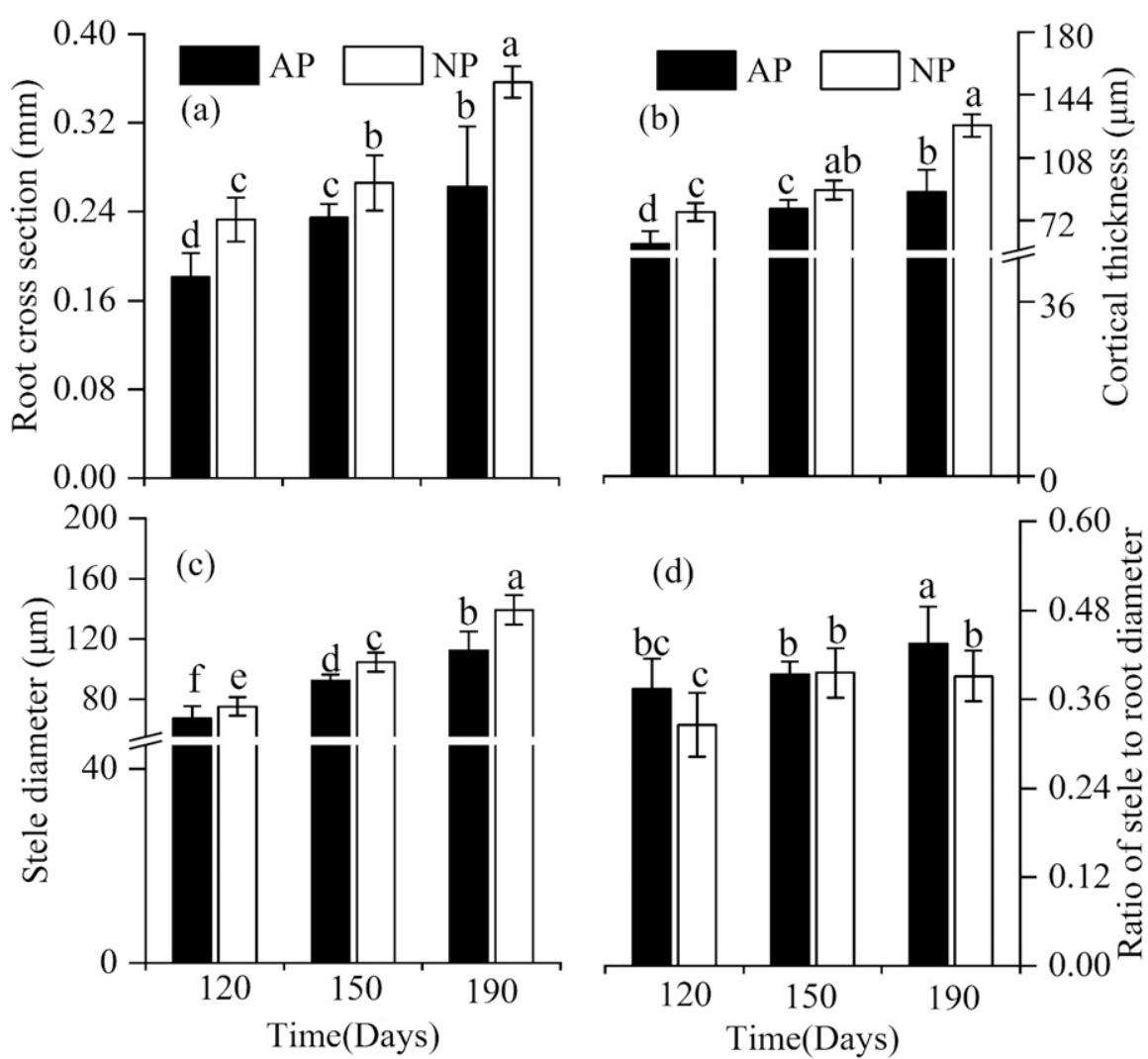

Fig. 5. Root cross section, cortical thickness, stele diameter, and ratio of stele to diameter of $\leq 0.5$ roots at 120,150 , and $190 \mathrm{~d}$ of the air-root-pruning (AP) (left panel) and non-root-pruning (NP) (right panel) in $P$. orientalis seedlings. The bars indicate the standard error $(n=9)$. Different lowercase letters represent significant differences $(P<0.05)$ in root traits among treatments according to Fisher's least significant difference test. genetic response to increase plant stability (Sun et al., 2008). Additionally, the root vitality of fine roots $(\leq 2 \mathrm{~mm})$ was greater under the AP treatment (Fig. 4B), implying that AP may promote the competitive and metabolic activities of fine roots (Comas et al., 2000; Dong et al., 2016; Ruf and Brunner, 2003).

According to the anatomical investigations, AP also influenced the root $(\leq 0.5 \mathrm{~mm})$ anatomy of $P$. orientalis (Fig. 5). Changes in the layers of the root $(\leq 0.5 \mathrm{~mm})$ cortical cells by AP may alter the cortex, which might be responsible for modifications of the root diameter of $P$. orientalis. More importantly, the AP seedlings displayed a significantly shorter taproot than the NP plants (Table 1). One possible explanation for this is that the taproot was restricted under AP, and subsequently, the cortical cells of the root tips were also impaired, thereby inhibiting taproot elongation (Table 1) and thus causing an increase in the proportion of fine roots as a type of compensatory response due to the shorter taproot (Fig. 4A). Another explanation could be that the stimulation of signal molecules, such as the plant hormone indole3 -acetic acid (IAA), may have increased the proportion of fine roots of $P$. orientalis under AP. It was recently reported that high concentrations of IAA could stimulate the formation of fine roots when the taproot length was restricted (Pacholczak et al., 2017; Pierret et al., 2007; Remans et al., 2008; Spaepen et al., 2007). Furthermore, we suggest that the enlarged taproot cross-section in response to AP might be attributed to the increased cortical thickness within the root crosssections of $P$. orientalis. In the present study, the stele diameter of the taproot remained unchanged under AP treatment for the first $120 \mathrm{~d}$ but increased at 150 and $190 \mathrm{~d}$ (Table 1). Because the root stele comprises vessels that form major conductive tissue, the proportion of the stele in root cross sections is mostly used as an indicator of water and nutrient transport potential from the root to shoots (Guo et al., 2008; Wang et al., 2016). Thicker taproots with a greater stele within a cross section are likely related to a higher potential for reducing various biotic and abiotic stresses in perennials (Alameda and Villar, 2012). These results collectively imply that air-root pruning of $P$. orientalis seedlings may provide more benefits to roots, possibly via the enhanced physiological and ecological functions, such as improved water and nutrient acquisition efficiencies (Zadworny et al., 2015), enhanced an increased absorptive capacity

Table 1. Changes in length and transverse sections of taproots on day 120, 150, and 190 by treatments.

\begin{tabular}{|c|c|c|c|c|c|c|c|c|c|}
\hline \multirow[b]{2}{*}{ Variables } & \multicolumn{3}{|c|}{$120 \mathrm{~d}$} & \multicolumn{3}{|c|}{$150 \mathrm{~d}$} & \multicolumn{3}{|c|}{$190 \mathrm{~d}$} \\
\hline & $\mathrm{AP}$ & NP & $P$ & AP & NP & $P$ & $\mathrm{AP}$ & NP & $P$ \\
\hline Taproot length $(\mathrm{cm})$ & $10.11 \pm 2.69 \mathrm{~d}$ & $11.78 \pm 2.09 \mathrm{c}$ & 0.03 & $10.40 \pm 2.35 \mathrm{~d}$ & $23.93 \pm 1.92 b$ & 0.04 & $10.70 \pm 1.32 \mathrm{~d}$ & $37.89 \pm 3.15 \mathrm{a}$ & 0.02 \\
\hline Cross section (mm) & $0.44 \pm 0.05 \mathrm{e}$ & $0.45 \pm 0.07 \mathrm{de}$ & 0.39 & $0.59 \pm 0.09 \mathrm{bc}$ & $0.51 \pm 0.01 \mathrm{~d}$ & 0.00 & $0.83 \pm 0.02 \mathrm{a}$ & $0.67 \pm 0.06 b$ & 0.00 \\
\hline Cortical thickness $(\mu \mathrm{m})$ & $137.54 \pm 6.99 \mathrm{~cd}$ & $139.41 \pm 10.75 \mathrm{~cd}$ & 0.73 & $180.53 \pm 11.58 b$ & $149.59 \pm 6.42 \mathrm{c}$ & 0.00 & $186.74 \pm 13.81 \mathrm{a}$ & $170.55 \pm 5.26 b$ & 0.00 \\
\hline Stele diameter $(\mu \mathrm{m})$ & $170.62 \pm 9.03 \mathrm{~cd}$ & $176.16 \pm 2.89 \mathrm{~cd}$ & 0.18 & $218.62 \pm 18.10 \mathrm{bc}$ & $200.74 \pm 9.93 \mathrm{bc}$ & 0.06 & $309.28 \pm 14.02 \mathrm{a}$ & $295.78 \pm 15.86 \mathrm{ab}$ & 0.15 \\
\hline
\end{tabular}


and greater mycorrhizal colonization (Mosca et al., 2017).

\section{Conclusion}

Morphological, physiological, and anatomical assessments revealed the response of $P$. orientalis roots to air exposure when grown in soil blocks. Our findings provide insights into the mechanisms associated with the improved root growth of $P$. orientalis at an early stage of growth under AP treatment. The results suggest that $P$. orientalis seedlings of AP are likely to perform better after transplantation compared with NP plants. Further research should aim to ascertain the efficacy of this treatment following field transplantation to ensure practical application, as well as investigate the benefit of AP for other plant species in northern China.

\section{Literature Cited}

Alameda, D. and R. Villar. 2012. Linking root traits to plant physiology and growth in Fraxinus angustifolia Vahl. seedlings under soil compaction conditions. Environ. Expt. Bot. 79:4957.

Amoroso, G., P. Frangi, R. Piatti, F. Ferrini, A. Fini, and M. Faoro. 2010. Effect of container design on plant growth and root deformation of littleleaf linden and field elm. HortScience 45:1824-1829.

Campbell, D.B., S. Kiiskila, L.J. Philip, J.J. Zwiazek, and M.D. Jones. 2006. Effects of forest floor planting and stock type on growth and root emergence of Pinus contorta seedlings in a cold northern cutblock. New For. 32:145-162.

Close, D.C., S. Paterson, R. Corkrey, and C. McArthur. 2010. Influences of seedling size, container type and mammal browsing on the establishment of Eucalyptus globulus in plantation forestry. New For. 39:105-115.

Comas, L.H., D.M. Eissenstat, A.N. Lakso, R. Norby, A. Fitter, and R. Jackson. 2000. Assessing root death and root system dynamics in a study of grape canopy pruning. New Phytol. 147:171-178.

Cui, Q.F., Z.P. Feng, and X.T. Yang. 2017. Distributions of fine and coarse tree roots in a semi-arid mountain region and their relationships with soil properties. Trees (Berl.) 31: 607-616.

Dara, A., B.A. Moradi, P. Vontobel, and S.E. Oswald. 2015. Mapping compensating root water uptake in heterogeneous soil conditions via neutron radiography. Plant Soil 397:273287.

Davis, A.S. and D.F. Jacobs. 2005. Quantifying root system quality of nursery seedlings and relationship to outplanting performance. New For. 30:295-311.

Dey, D.C., E.S. Gardiner, J.M. Kabrick, J.A. Stanturf, and D.F. Jacobs. 2010. Innovations in afforestation of agricultural bottomlands to restore native forests in the eastern USA. Scand. J. For. Res. 25:31-42.

Di Iorio, A., V. Giacomuzzi, and D. Chiatante. 2016. Acclimation of fine root respiration to soil warming involves starch deposition in very fine and fine roots: A case study in Fagus sylvatica saplings. Physiol. Plant. 156:294 310.

Dong, T.F., B.L. Duan, S. Zhang, H. Korpelainen, U. Niinemets, and C.Y. Li. 2016. Growth, biomass allocation and photosynthetic responses are related to intensity of root sever- ance and soil moisture conditions in the plantation tree Cunninghamia lanceolata. Tree Physiol. 36:807-817.

Dumroese, R.K., S.J.S. Sung, J.R. Pinto, A. RossDavis, and D.A. Scott. 2013. Morphology, gas exchange, and chlorophyll content of longleaf pine seedlings in response to rooting volume, copper root pruning, and nitrogen supply in a container nursery. New For. 44:881-897.

Feng, Z.P., G.G. Yang, E.H. Guo, Q.F. Cui, B. Pei, and X.T. Yang. 2017. Effect of air root pruning on biomass allocation and root growth in Platycladus orientalis seedlings. Acta Ecol. Sin. 23:7854-7861. (In Chinese).

Guo, D.L., M.X. Xia, X. Wei, W.J. Chang, Y. Liu, and Z.Q. Wang. 2008. Anatomical traits associated with absorption and mycorrhizal colonization are linked to root branch order in twenty-three Chinese temperate tree species. New Phytol. 180:673-683.

Jiang, Y., B.Q. Wang, M.Y. Dong, Y.M. Huang, M.C. Wang, and B. Wang. 2014. Response of daily stem radial growth of Platycladus orientalis to environmental factors in a semi-arid area of North China. Trees (Berl.) 29:87-96.

Li, X., Q.F. Xiao, J.Z. Niu, S. Dymond, N.S. Van Doorn, X.X. Yu, B.Y. Xie, X.Z. Lv, K.B. Zhang, and J. Li. 2016. Process-based rainfall interception by small trees in Northern China: The effect of rainfall traits and crown structure characteristics. Agr. For. Meteorol. 218 219:65-73.

Lindström, A. and G. Rune. 1999. Root deformation in plantations of container-grown Scots pine trees: Effects on root growth, tree stability and stem straightness. Plant Soil 217:29-37.

Liu, J.J., M. Bloomberg, G.L. Li, and Y. Liu. 2016. Effects of copper root pruning and radicle pruning on first-season field growth and nutrient status of Chinese cork oak seedlings. New For. 47:715-729.

Makita, N., J. Pumpanen, K. Köster, and F. Berninger. 2016. Changes in very fine root respiration and morphology with time since last fire in a boreal forest. Plant Soil 402:303316.

Mariotti, B., A. Maltoni, D.F. Jacobs, and A. Tani. 2015. Container effects on growth and biomass allocation in Quercus robur and Juglans regia seedlings. Scand. J. For. Res. 30:401415.

Marler, T. and C. Musser. 2016. Chemical and air pruning of roots influence post-transplant root traits of the critically endangered Serianthes nelsonii. Plant Root 10:21-25.

McClaugherty, C.A., J.D. Aber, and J.M. Melillo. 1982. The role of fine roots in the organic matter and nitrogen budgets of two forested ecosystems. Ecology 63:1481-1490.

McCormack, M.L., I.A. Dickie, D.M. Eissenstat, T.J. Fahey, C.W. Fernandez, D.L. Guo, H.S. Helmisaari, E.A. Hobbie, C.M. Iversen, R.B. Jackson, J.L. Leppälammi-Kujansuu, R.J. Norby, R.P. Phillips, K.S. Pregitzer, S.J. Pritchard, B. Rewald, and M. Zadworny. 2015. Redefining fine roots improves understanding of belowground contributions to terrestrial biosphere processes. New Phytol. 207:505-518.

Mosca, E., L. Montecchio, G. Barion, C. Dal Cortivo, and T. Vamerali. 2017. Combined effects of thinning and decline on fine root dynamics in a Quercus robur L. forest adjoining the Italian Pre-Alps. Ann. Bot. 119:12351246.

Ortega, U., J. Majada, A.M. Petite, A. Mena-Petite, J. Sanchez-Zabala, N. Rodriguez-Iturrizar, K. Txarterina, J. Azpitarte, and M. Duñabeitia. 2006. Field performance of Pinus radiata D.
Don produced in nursery with different types of containers. New For. 31:97-112.

Pacholczak, A., A. Jędrzejuk, and M. Sobczak. 2017. Shading and natural rooting biostimulator enhance potential for vegetative propagation of dogwood plants (Cornus alba L.) via stem cuttings. S. Afr. J. Bot. 109:34-41.

Perrig, D., M.L. Boiero, O.A. Masciarelli, C. Penna, O.A. Ruiz, F.D. Cassán, and M.V. Luna. 2007. Plant-growth-promoting compounds produced by two agronomically important strains of Azospirillum brasilense, and implications for inoculant formulation. Appl. Microbiol. Biotechnol. 75:1143-1150.

Pierret, A., C. Doussan, Y. Capowiez, F. Bastardie, and L. Pagès. 2007. Root functional architecture: A framework for modeling the interplay between roots and soil. Vadose Zone J. 6:269-281.

Pregitzer, K.S., J.L. Deforest, A.J. Burton, M.F. Allen, R.W. Ruess, and R.L. Hendrick. 2002. Fine root architecture of nine North American trees. Ecol. Monogr. 72:293-309.

Rao, I.M., J.W. Miles, S.E. Beebe, and W.J. Horst. 2016. Root adaptations to soils with low fertility and aluminium toxicity. Ann. Bot. 118:593-605.

Reinmann, A.B. and P.H. Templer. 2015. Reduced winter snowpack and greater soil frost reduce live root biomass and stimulate radial growth and stem respiration of red maple (Acer rubrum) trees in a mixed-hardwood forest. Ecosystems (N. Y.) 19:129-141.

Remans, R., S. Beebe, M. Blair, G. Manrique, E. Tovar, I. Rao, A. Croonenborghs, R. TorresGutierrez, M. El-Howeity, J. Michiels, and J. Vanderleyden. 2008. Physiological and genetic analysis of root responsiveness to auxinproducing plant growth-promoting bacteria in common bean (Phaseolus vulgaris L.). Plant Soil 302:149-161.

Ruf, M. and I. Brunner. 2003. Vitality of tree fine roots: Reevaluation of the tetrazolium test. Tree Physiol. 23:257-263.

Rune, G. 2003. Slits in container wall improve root structure and stem straightness of outplanted Scots pine seedlings. Silva Fenn. 37:333-342.

Seago, J.L., Jr. and D.D. Fernando. 2013. Anatomical aspects of angiosperm root evolution. Ann. Bot. 112:223-238.

Spaepen, S., J. Vanderleyden, and R. Remans. 2007. Indole-3-acetic acid in microbial and microorganism-plant signaling. FEMS Microbiol. Rev. 31:425-448.

Sudmeyer, R.A., J. Speijers, and B.D. Nicholas. 2004. Root distribution of Pinus pinaster, $P$. radiata, Eucalyptus globulus and E. kochii and associated soil chemistry in agricultural land adjacent to tree lines. Tree Physiol. 24:1333-1346.

Sun, H.L., S.C. Li, W.L. Xiong, Z.R. Yang, B.S Cui, and T. Yang. 2008. Influence of slope on root system anchorage of Pinus yunnanensis. Ecol. Eng. 32:60-67.

Takoutsing, B., Z. Tchoundjeu, A. Degrande, E. Asaah, A. Gyau, F. Nkeumoe, and A. Tsobeng. 2014. Assessing the quality of seedlings in small-scale nurseries in the Highlands of Cameroon: The use of growth characteristics and quality thresholds as indicators. Smallscale For. 13:65-77.

Tsakaldimi, M., T. Zagas, T. Tsitsoni, and P. Ganatsas. 2005. Root morphology, stem growth and field performance of seedlings of two Mediterranean evergreen oak species raised in different container types. Plant Soil 278:85-93

Tsakaldimi, M., P. Ganatsas, and D.F. Jacobs. 2013. Prediction of planted seedling survival of five Mediterranean species based on initial seedling morphology. New For. 44:327-339. 
Tian, H.Y., I. De-Smet, and Z.J. Ding. 2014. Shaping a root system: Regulating lateral versus primary root growth. Trends Plant Sci. 19:426-431.

Van Sambeek, J.W., L.D. Godsey, W.D. Walter, H.E. Garrett, and J.P. Dwyer. 2016. Field performance of Quercus bicolor established as repeatedly airroot-pruned container and bareroot planting stock. Open J. For. 6:163-176.

Villar-Salvador, P., J. Puértolas, B. Cuesta, J.L. Peñuelas, M. Uscola, N. Heredia-Guerrero, and J.M. Bey Benayas. 2012. Increase in size and nitrogen concentration enhances seedling survival in Mediterranean plantations. Insights from an ecophysiological conceptual model of plant survival. New For. 43:755-770.

Wang, Y., X.Y. Dong, H.F. Wang, Z.Q. Wang, and J.C. Gu. 2016. Root tip morphology, anatomy, chemistry and potential hydraulic conductivity vary with soil depth in three temperate hardwood species. Tree Physiol. 36:99-108.
Wang, Z.Q., D.L. Guo, X.R. Wang, J.C. Gu, and M. Li. 2006. Fine root architecture, morphology, and biomass of different branch orders of two Chinese temperate tree species. Plant Soil 288:155-171.

Watson, A.J. and J.D. Tombleson. 2002. Toppling in juvenile pines: A comparison of the root system characteristics of direct-sown seedlings, and bare-root seedlings and cuttings. Plant Soil 239:187-196.

Wu, J., Q. Zhang, and F. Yang. 2017. Does shortterm litter input manipulation affect soil respiration and its carbon-isotopic signature in a coniferous forest ecosystem of central China? Appl. Soil Ecol. 113:45-53.

Yang, X.T., N. Sajiki, Z. Yang, L.L. Zeng, and P.L. Zhu. 2010. Effects of different seedling stock types on root growth of Platycladus orientalis and Ulmus pumilas transplants. Acta Ecol. Sin. 30:86-92. (In Chinese).
Yang, X.T., N.L. Dong, D.F. Yan, N. Sajiki, and Y. Zhao. 2011. The growth and distribution of Platycladus orientalis seed-base seedling root in different culture periods. Acta Ecol. Sin. 31:5818-5823. (In Chinese).

Yu, X., X. Liu, Z. Zhao, J.L. Liu, and C.X. Zhang. 2015. Effect of monospecific and mixed seabuckthorn (Hippophae rhamnoides) plantations on the structure and activity of soil microbial communities. PLoS One 10:E0117505.

Zadworny, M., M.L. Mccormack, K. Rawlik, and A.M. Jagodziński. 2015. Seasonal variation in chemistry, but not morphology, in roots of Quercus robur growing in different soil types. Tree Physiol. 35:644-652.

Zhang, H.D., W. Wei, L.D. Chen, and L. Yang. 2017. Evaluating canopy transpiration and water use of two typical planted tree species in the dryland Loess Plateau of China. Ecohydrology 10:E1830. 